\title{
The Effect of I131 Treatment on Pregnancy Outcomes after Thyroidectomy in Patients with Differentiated Thyroid Carcinoma: A Meta-Analysis
}

\author{
Lijuan Zhang ${ }^{1}$, Yinqiong Huang ${ }^{1}$, Yuanyuan Zheng ${ }^{1}$, Liangchun $\mathrm{Cai}^{1}$, Junping Wen ${ }^{1}$, and \\ Gang Chen ${ }^{1}$ \\ ${ }^{1}$ Fujian Medical University
}

May 5, 2020

\begin{abstract}
Objectives: This meta-analysis aims to investigate the association between I131 treatment and pregnancy outcomes. Methods: Electronic database PubMed, Embase and the Cochrane Library were throughly searched until December 2017. Databases were searched for studies that reported the incidence of pregnancy outcomes (spontaneous abortion, induce abortion, premature birth, stillbirth) in DTC participants with I131 treatment or not. Meta-analysis was performed in Stata/SE12. A random or fixed effects model was adopted according to the result of heterogeneity test. Results: A total of 6 observational studies were eligible, involving 14132 participants and 2969 pregnancies. It showed that postoperative I131 treatment for DTC had no significant effect on spontaneous abortion $(\mathrm{OR}=1.05, \mathrm{P}=0.701)$, induced abortion $(\mathrm{OR}=1.06, \mathrm{P}=0.859)$, abortion $(\mathrm{OR}=1.07, \mathrm{P}$ $=0.597)$, premature birth $(\mathrm{OR}=1.49, \mathrm{P}=0.073)$ and stillbirth $(\mathrm{OR}=1.58, \mathrm{P}=0.364)$. The group in which interval time between last I131 treatment and pregnancy $>1$ year had significantly lower risk of abortion than with interval $<1$ year $(\mathrm{OR}$ $=0.50, \mathrm{P}=0.000$. Conclusions: I131 treatment for DTC had no significant effect on pregnancy outcomes. Pregnancy is not recommended for DTC patients within 1 year after 131I treatment.
\end{abstract}

\section{Introduction}

Differentiated thyroid carcinoma (DTC) includes thyroid papillary carcinoma and thyroid follicular carcinoma, accounting for more than $90 \%$ of all thyroid cancers (1). After performing thyroidectomy, radioiodine is widely employed for the ablation of residual thyroid tissue, which plays an important role in reducing the recurrence rate and mortality(2). However, radioiodine treatment may damage radiation-sensitive tissues such as salivary glands, lung, gut, bone marrow, gonads. Due to the high sensitivity of gonads to ionizing radiation, the effect of $\mathrm{I}^{131}$ therapy on reproductive health cannot be ignored. $\mathrm{I}^{131}$ therapy may result in abortions, premature birth, stillbirth and so on (2-7). In addition, the effect of $\mathrm{I}^{131}$ treatment on male DTC patients was also studied. Some studies have shown that a single $\mathrm{I}^{131}$ treatment does not produce sufficient permanent radiation damage to the testis, but continued high-dose treatment can cause permanent damage and can cause infertility (8-10). The aim of the present systematic review was to evaluate the effect of post-operative $\mathrm{I}^{131}$ treatment on pregnancy outcomes, and to investigate the best interval time between last $\mathrm{I}^{131}$ treatment and pregnancy.

\section{Methods}

This study was carried out following the guidelines suggested in the PRISMA statement to ensure the quality of reporting items in meta-analyses (11).

\section{Data sources and searches}


A systematic search was performed in the electronic database including PubMed, Embase, Cochrane Library, CNKI, VIP by December, 2017. Combination of subject terms and keywords were used to locate studies reported on differentiated thyroid cancer, thyroid carcinoma, radioiodine, $\mathrm{I}^{131}$, pregnancy outcomes, abortion and preterm birth. The searches were independently performed by two reviewers.

\section{Study selection:}

A total of 719 relevant studies were retrieved in the database. After duplicate studies $(n=102)$ were removed by the EndNote software, 617 studies were included. One author reviewed the titles and/or abstracts of the 617 studies. Studies that provided the pregnancy outcomes in DCT patients who received ${ }^{131}$ treatment and those who didn't receive ${ }^{131}$ treatment were included. Then, 609 studies were excluded because these studies didn't definitively diagnose patients with DTC, didn't use I ${ }^{131}$ treatment, didn't evaluate pregnancy outcomes. Animal studies, in vitro experiments, reviews, conference documents, abstracts, case reports were excluded. The remaining eight studies were further read in detail, among which two were further excluded for the following reasons: (1) The control group was not patients with DTC; (2) The number of cases of pregnancy was not provided. Finally, six studies were included. One author confirmed that these studies met the inclusion criteria.

\section{Data extraction and quality assessment:}

The documents retrieved from PubMed, Embase, Cochrane Library etc. were all imported into the EndNote X7. After the duplicate literature was excluded, the two researchers independently performed the review of the literature according to the criteria. The data sheet includes detailed information on basic information included in the study: first author, publication time, study area, study year, number of pregnancy, population characteristics (gender, age, medical history, personal history) of the observation group and control group, the dose of $\mathrm{I}^{131}$, interval time between last $\mathrm{I}^{131}$ treatment and pregnancy, pregnancy outcomes and follow-up time.

The evaluation of methodological quality of each study was performed with the Newcastle-Ottawa Scale (NOS) (12). It consists of eight items regarding the methodology applied for describing selection of study group, comparability of the groups, and exposure ascertainment. The resulting score ranges between zero to nine. A higher score represents a better methodological quality. The studies with scores higher than 5 stars were considered high quality.

\section{Statistical method}

Statistical analysis was carried out using Stata/SE 12.0. Odds radio (OR) with pertinent $95 \%$ confidence intervals (CI) were used for dichotomous variables. A $P<0.05$ is considered statistically significant. Statistical heterogeneity was assessed with the Cochrane $\mathrm{Q}$ test and with the $\mathrm{I}^{2}$ statistic. If heterogeneity was statistically significant $\left(P[?] 0.1, \mathrm{I}^{2}>50 \%\right)$, a random-effect model was used to pool the result. If heterogeneity was low ( $P$ i.0.1, $\mathrm{I}^{2}[?] 50 \%$ ), a fixed-effect model was used. The forest plots is used to represent the statistical results of the meta-analysis.

A sensitivity analysis was performed to evaluate robustness of the results of the model by excluding one study, and the results were assessed as for whether they were substantially influenced by a specific study.

Publication bias was assessed by the Egger's and Begg's tests. AP $<0.10$ is considered statistically significant.

\section{Funding}

This research did not receive any specific grant from funding agencies in the public, commercial, or not-forprofit sectors.

\section{Results}

\section{Literature search results}


A total of 719 relevant studies were retrieved in the database. Most were excluded because these studies didn't mention patients of DTC, postoperative $\mathrm{I}^{131}$ treatment or pregnancy outcomes. And then studies that are uncontrolled studies, the outcome data not clearly stated, research population not meet the requirements were excluded. Finally, six studies(13-18) were included (Fig. 1), including 14132 participants and 2696 pregnancies (Table 1). All of the six articles were considered as high quality.

\section{Meta-analysis result}

\section{Spontaneous abortion}

In the six studies included(13-18), there were 1825 cases of pregnancy and 228 cases of spontaneous abortion in the $I^{131}$ treatment group, as well as 1144 cases of pregnancy and 126 cases of spontaneous abortion in the non- $\mathrm{I}^{131}$ treatment group. A fixed-effect model was used according to the heterogeneity test result $(P$ $\left.=0.530 ; \mathrm{I}^{2}=0.0 \%\right)$. Postoperative $\mathrm{I}^{131}$ treatment for DTC had no significant effect on spontaneous abortion $(\mathrm{OR}=1.05,95 \%$ CI $0.82-1.33, P=0.701$; Fig. 2(1)). The robustness of the result of the model was suggested by sensitivity analysis (Fig. 3). According to Egger's test $(P=0.877)$ and Begg's test $(P=$ 0.707), no evidence of publication bias was found.

\section{Induced abortion}

Among four studies included(14-17), there were 983 cases of pregnancy and 190 cases of induced abortion in the $\mathrm{I}^{131}$ treatment group, as well as 408 cases of pregnancy and 67 cases of induced abortion in the non- ${ }^{131} \mathrm{I}$ treatment group. A random-effect model was used according to the heterogeneity test result $\left(P=0.036 ; \mathrm{I}^{2}\right.$ $=65.0 \%)$. Postoperative $\mathrm{I}^{131}$ treatment for DTC had no significant effect on induced abortion $(\mathrm{OR}=1.06$, 95\% CI 0.57-1.98, $P=0.859$; Fig. 2(2)).

\section{Abortion(Spontaneous abortion+ Induced abortion)}

Among four studies included(14-17), DTC postoperative $\mathrm{I}^{131}$ treatment had no significant effect on abortion $(\mathrm{OR}=1.07,95 \%$ CI $0.83-1.39, P=0.597$; Fig. 2(3)).

\section{Preterm birth}

Among four studies included(13-15, 18), there were 1216 cases of pregnancy and 62 cases of preterm birth in the ${ }^{131}$ I treatment group, as well as 931 cases of pregnancy and 33 cases of preterm birth in the non- $\mathrm{I}^{131}$ treatment group. A fixed effect model was used according to the heterogeneity test result $\left(P=0.590 ; \mathrm{I}^{2}=\right.$ $0.0 \%)$. Postoperative $\mathrm{I}^{131}$ treatment for DTC had no significant effect on preterm birth $(\mathrm{OR}=1.49,95 \% \mathrm{CI}$ 0.96-2.30, $P=0.073$; Fig. 2(4)).

\section{Stillbirth}

Among three studies included(14-16), there were 859 cases of pregnancy and 7 cases of stillbirth in the $\mathrm{I}^{131}$ treatment group, as well as 307 cases of pregnancy and 3 cases of stillbirth in the non- $\mathrm{I}^{131}$ treatment group. A fixed effect model was used according to the heterogeneity test result $\left(P=0.507 ; \mathrm{I}^{2}=0.0 \%\right)$. Postoperative $\mathrm{I}^{131}$ treatment for DTC had no significant effect on stillbirth (OR $=0.58,95 \%$ CI $0.18-1.88, P$ $=0.364$; Fig. 2(5)).Interval time and abortionThree studies investigated the interval time between last $\mathrm{I}^{131}$ treatment and pregnancy and abortion(14-16). The group with interval $>1$ year involved 588 cases of pregnancy and 175 cases of abortions. There are 269 cases of pregnancy in the group with interval time $<$ 1 year, involving 123 cases of abortions. A fixed effect model was used according to the heterogeneity test result $\left(P=0.797 ; \mathrm{I}^{2}=0.0 \%\right)$. The risk of the abortion in the group with interval of last $\mathrm{I}^{131}$ treatment and pregnancy $>1$ year was lower than $<1$ year $(\mathrm{OR}=0.50,95 \%$ CI $0.37-0.68, P=0.000 ;$ Fig. 2(6)). Sensitivity analysis shows the result was robustness. According to Egger's test $(P=0.385)$ and Begg's test $(P=1.000)$, no evidence of publication bias was found.

\section{Discussion}

This systematic review has provided insight into the effects of post-operative $\mathrm{I}^{131}$ treatment on pregnancy outcomes, and to investigate the best interval time between last $\mathrm{I}^{131}$ treatment and pregnancy. 
In this meta-analysis, postoperative $\mathrm{I}^{131}$ treatment for DTC had no significant effect on spontaneous abortion $(\mathrm{OR}=1.05, P=0.701)$. This is consistent with data from other studies (19-21), showing that the spontaneous abortion rate in patients with DTC after $\mathrm{I}^{131}$ treatment was $2.2 \%-20 \%$, which was not significant different from that in the general population. There are many factors affecting spontaneous abortion, such as embryonic chromosome abnormalities, mother's previous abortion history and living habits. In this study, all patients underwent thyroid hormones replacement therapy and tested for normal levels of thyroid function.

This meta-analysis suggested that postoperative ${ }^{131}$ treatment for DTC had no significant effect on induced abortion $(\mathrm{OR}=1.06, P=0.859)$. There are many subjective factors that can lead to induced abortion, such as the patient's personal fertility desire, cultural and life environment, including the patient's psychological response to DTC and I ${ }^{131}$ treatment. The reason for the induced abortions in most cases was the mother's concern about possible offspring complications(18). Some women underwent abortions because prenatally abnormal, which can indirectly reflect the effect of $\mathrm{I}^{131}$ on induce abortion. The reasons for induced abortion in patients were not mentioned in the five studies included.

Sarkar S D et al reported that the preterm rate in male and female DTC patients after receiving $\mathrm{I}^{131}$ treatment was $8 \%(6 / 71)((22)$, which was not statistically different from that in the general population. In the current study, we have further supported the result. We found that postoperative $\mathrm{I}^{131}$ treatment for DTC had no significant effect on preterm birth $(\mathrm{OR}=1.49, P=0.073)$.

Studies (13-15) showed that there was no significant relationship between the incidence of stillbirth and $\mathrm{I}^{131}$ treatment in DTC patients. This meta-analysis showed that the $\mathrm{I}^{131}$ treatment had no significant effect on induced abortion $(\mathrm{OR}=0.58, P=0.364)$. Causes of stillbirth include abnormalities of the placenta, severe fetal abnormalities, severe pregnancy complications, complications, etc. However, the association between the incidence of the cause and $\mathrm{I}^{131}$ treatment has not been reported.

To investigate the best interval between the last administration of $\mathrm{I}^{131}$ and pregnancy, we compared the abortion risk between patients with interval $>1$ year and $<1$ year. We found that compared with patients with interval $<1$ year, patients with interval $>1$ year had significant lower risk of abortion $(\mathrm{OR}=0.50, P$ $=0.000$ ). The findings are confirmed by statistical method, sensitivity analysis and publication bias analysis. Fard-Esfahani A et al suggested that there was statistically significant difference between two time intervals, that was, the interval between the last $\mathrm{I}^{131}$ treatment and spontaneous abortion $(16.20 \pm 10.97$ months $)$ and the interval between the last treatment and normal pregnancy (32.10 \pm 18.22 months) (17). Studies (8-10, 23-28)found that $\mathrm{I}^{131}$ in the blood, urine, and feces can cause radiation-induced injury to the gonads, which may lead to temporary amenorrhea or a decrease in menstrual flow. Besides, amenorrhea and irregular menstruation lasted for 6-12 months after $\mathrm{I}^{131}$ treatment, but no permanent ovarian failure was found. For male reproductive health, Studies $(10,28,29)$ showed that there would be a transient decrease in sperm count and vitality, as well as testis volume after $\mathrm{I}^{131}$ treatment. Wichers $\mathrm{M}$ et al found that inhibin B decreased significantly after 3 to 6 months of $\mathrm{I}^{131}$ treatment, and rose to normal after 18 months later(27). In addition, it can also result in increased FSH as well as decreased AMH, suggesting that gonad function is affected. Moreover, the gonad function returns to normal after 1 year. The American Thyroid Association recommends that women should avoid pregnancy within 6-12 months, and men within 6 months of contraception after receiving $\mathrm{I}^{131}$ treatment for DTC the ((19). In previous studies, comparative analyses on the interval 0-6 and 6-12 (months) were rarely conducted. Therefore, more large-scale prospective studies are needed to establish the more precise recommended safe interval.

The present study had several limitations, there may be a small number of articles included, and the type of study is not a randomized controlled trial. It is possible that the retrieval of research was incomplete with the search strategy and terms used; And the measurement of pregnancy outcome may be inaccurate. It is probable that not all abortions were in the medical records, as some would have occurred outside a medical setting. This raised the possibility of biased ascertainment. Additional and specifically designed studies are needed. For example, the effects of $\mathrm{I}^{131}$ treatment in DTC patients on genes of offspring, congenital disorders of offspring, growth and development of offspring. At the same time, more basic researches are needed to explore the mechanism of $\mathrm{I}^{131}$ treatment on the reproductive system. 
Conclusion

In summary, in the present systematic review and meta-analysis, postoperative $\mathrm{I}^{131}$ treatment for DTC had no significant effect on spontaneous abortion, induced abortion, premature birth and stillbirth. Patients with interval between last $\mathrm{I}^{131}$ treatment and pregnancy $>1$ year had significant lower risk of abortion than that with interval $<1$ year. Therefore, $\mathrm{I}^{131}$ treatment doesn't increase the chance of adverse pregnancy outcomes. Pregnancy is not recommended for DTC patients within 1 year after ${ }^{131}$ I treatment.

\section{Acknowledgments}

We thank the authors of the studies included this paper for their response to the requests for additional information

\section{Conflict of Interest}

\section{None.}

\section{Authors' roles}

LZ and YH contributed to the study equally. LZ and YH performed the data acquisition, analysed the data, wrote and revised the manuscript and approved the submitted version. GC designed the studies, revised the manuscript and approved the submitted version. YZ, LC and JW revised the manuscript and approved the submitted version.

\section{References}

1. Sherman SI. Thyroid carcinoma. Lancet (London, England) 2003 Feb 8;361(9356):501-11.

2. DiRusso G, Kern KA. Comparative analysis of complications from I-131 radioablation for welldifferentiated thyroid cancer. Surgery 1994 Dec;116(6):1024-30.

3. Solans R, Bosch JA, Galofre P, Porta F, Rosello J, Selva-O'Callagan A, et al. Salivary and lacrimal gland dysfunction (sicca syndrome) after radioiodine therapy. Journal of nuclear medicine : official publication, Society of Nuclear Medicine 2001 May;42(5):738-43.

4. L C. Pulmonary fibrosis following radioiodine therapy of pulmonary metastases from differentiated thyroid carcinoma. Thyroid 2010;3(20).

5. Hebestreit H, Biko J, Drozd V, Demidchik Y, Burkhardt A, Trusen A, et al. Pulmonary fibrosis in youth treated with radioiodine for juvenile thyroid cancer and lung metastases after Chernobyl. European journal of nuclear medicine and molecular imaging 2011 Sep;38(9):1683-90.

6. Sioka C, Fotopoulos A. Effects of I-131 therapy on gonads and pregnancy outcome in patients with thyroid cancer. Fertility and Sterility 2011;95(5):1552-9.

7. Fard-Esfahani A, Emami-Ardekani A, Fallahi B, Fard-Esfahani P, Beiki D, Hassanzadeh-Rad A, et al. Adverse effects of radioactive iodine-131 treatment for differentiated thyroid carcinoma. Nuclear Medicine Communications 2014;35(8):808-17.

8. Pacini F, Gasperi M, Fugazzola L, Ceccarelli C, Lippi F, Centoni R, et al. Testicular function in patients with differentiated thyroid carcinoma treated with radioiodine. Journal of nuclear medicine : official publication, Society of Nuclear Medicine 1994 Sep;35(9):1418-22.

9. Hyer S, Vini L, O'Connell M, Pratt B, Harmer C. Testicular dose and fertility in men following L131 therapy for thyroid cancer. Clinical Endocrinology 2002;56(6):755-8.

10. Canale D, Ceccarelli C, Caglieresi C, Moscatelli A, Gavioli S, Santini P, et al. Effects of radioiodine treatment for differentiated thyroid cancer on testis function. Clinical Endocrinology 2014. 
11. Panic N, Leoncini E, De BG, Ricciardi W, Boccia S. Evaluation of the endorsement of the preferred reporting items for systematic reviews and meta-analysis (PRISMA) statement on the quality of published systematic review and meta-analyses. Plos One 2013;8(12):e83138.

12. Wells GA, Shea BJ, O'Connell D, Peterson J, Welch V, Losos M, et al. The Newcastle-Ottawa Scale (NOS) for Assessing the Quality of Non-Randomized Studies in Meta-Analysis. Applied Engineering in Agriculture 2012;18(6):págs. 727-34.

13. Dottorini ME, Lomuscio G, Mazzucchelli L, Vignati A, Colombo L. Assessment of female fertility and carcinogenesis after iodine-131 therapy for differentiated thyroid carcinoma. Journal of nuclear medicine : official publication, Society of Nuclear Medicine 1995 Jan;36(1):21-7.

14. Schlumberger M, De Vathaire F, Ceccarelli C, Delisle MJ, Francese C, Couette JE, et al. Exposure to radioactive iodine-131 for scintigraphy or therapy does not preclude pregnancy in thyroid cancer patients. Journal of nuclear medicine : official publication, Society of Nuclear Medicine 1996;37(4):606-12.

15. Chow SM, Yau S, Lee SH, Leung WM, Law SC. Pregnancy outcome after diagnosis of differentiated thyroid carcinoma: no deleterious effect after radioactive iodine treatment. International journal of radiation oncology, biology, physics 2004 Jul 15;59(4):992-1000.

16. Garsi JP, Schlumberger M, Rubino C, Ricard M, Labbe M, Ceccarelli C, et al. Therapeutic administration of 131I for differentiated thyroid cancer: radiation dose to ovaries and outcome of pregnancies. Journal of nuclear medicine : official publication, Society of Nuclear Medicine 2008 May;49(5):845-52.

17. Fard-Esfahani A, Hadifar M, Fallahi B, Beiki D, Eftekhari M, Saghari M, et al. Radioiodine treatment complications to the mother and child in patients with differentiated thyroid carcinoma. Hellenic Journal of Nuclear Medicine 2009;12(1):37-40.

18. Ko KY, Yen RF, Lin CL, Cheng MF, Huang WS, Kao CH. Pregnancy outcome after I-131 therapy for patients with thyroid cancer a nationwide population-based cohort study. Medicine (United States) 2016;95(5).

19. Haugen BR, Alexander EK, Bible KC, Doherty GM, Mandel SJ, Nikiforov YE, et al. 2015 American Thyroid Association Management Guidelines for Adult Patients with Thyroid Nodules and Differentiated Thyroid Cancer: The American Thyroid Association Guidelines Task Force on Thyroid Nodules and Differentiated Thyroid Cancer. Thyroid 2016;26(1):1-133.

20. Lin JD, Wang HS, Weng HF, Kao PF. Outcome of pregnancy after radioactive iodine treatment for well differentiated thyroid carcinomas. Journal of Endocrinological Investigation 1998;21(10):662-7.

21. Einhorn J, Hulten M, Lindsten J, Wicklund H, Zetterqvist P. Clinical and cytogenetic investigation in children of parents treated with radioiodine. Acta radiologica: therapy, physics, biology 1972 Jun;11(3):193208.

22. Sarkar SD, Beierwaltes WH, Gill SP, Cowley BJ. Subsequent fertility and birth histories of children and adolescents treated with 131I for thyroid cancer. Journal of Nuclear Medicine 1976;17(6):460-4.

23. Sioka C, Kouraklis G, Zafirakis A, Manetou A, Dimakopoulos N. Menstrual cycle disorders after therapy with iodine-131. Fertility and Sterility 2006;86(3):625-8.

24. Souza Rosario PW, Alvarenga Fagundes T, Villas-Boas Fagundes AS, Barroso AL, Lamego Rezende L, Lanza Padrao E, et al. Ovarian function after radioiodine therapy in patients with thyroid cancer. Experimental and clinical endocrinology \& diabetes : official journal, German Society of Endocrinology [and] German Diabetes Association 2005 Jun;113(6):331-3.

25. Esfahani AF, Eftekhari M, Zenooz N, Saghari M. Gonadal function in patients with differentiated thyroid cancer treated with (131)I. Hellenic journal of nuclear medicine 2004 Jan-Apr;7(1):52-5. 
26. Vini L, Hyer S, Al-Saadi A, Pratt B, Harmer C. Prognosis for fertility and ovarian function after treatment with radioiodine for thyroid cancer. Postgraduate Medical Journal 2002;78(916):92-3.

27. Wichers M, Benz E, Palmedo H, Biersack HJ, Grunwald F, Klingmuller D. Testicular function after radioiodine therapy for thyroid carcinoma. European journal of nuclear medicine 2000 May;27(5):503-7.

28. Handelsman DJ, Turtle JR. Testicular damage after radioactive iodine (I-131) therapy for thyroid cancer. Clinical Endocrinology 1983;18(5):465-72.

29. Esfahani AF, Eftekhari M, Zenooz N, Fallahi B, Saghari M. Gonadal function in patients with differentiated thyroid cancer treated with 131I. Hellenic Journal of Nuclear Medicine 2004;7(1):52-5.

\section{Legend}

Table 1. Demographic and clinical data of subjects enrolled in studies.

Figure 1. Preferred reporting items for systematic reviews and meta-analyses flow diagram.

Figure 2. Forest plots of differences in the incidence of Pregnant outcomes between

the I131 and no I131treated groups. (1)Forest plots of differences in the incidence of spontaneous abortion between the I131 and no I131treated groups. (2)Forest plots of the incidence of induce abortion in the I131 and no I131treated groups. (3)Forest plots of differences in the incidence of abortion between I131 and no I131treated groups. (4)Forest plots of the incidence of Preterm birth in the I131 and no I131treated groups. (5)Forest plots of differences in the incidence of stillbirth between the I131 and no I131 treated groups. (6)Forest plots of differences in the incidence of abortion between the interval time of last I131 treatment and pregnancy $>1$ year and $<1$ year.

Figure 3. Sensitivity analysis of the incidence of spontaneous abortion in the $\mathrm{I}^{131}$ and no $\mathrm{I}^{131}$ treated groups. 


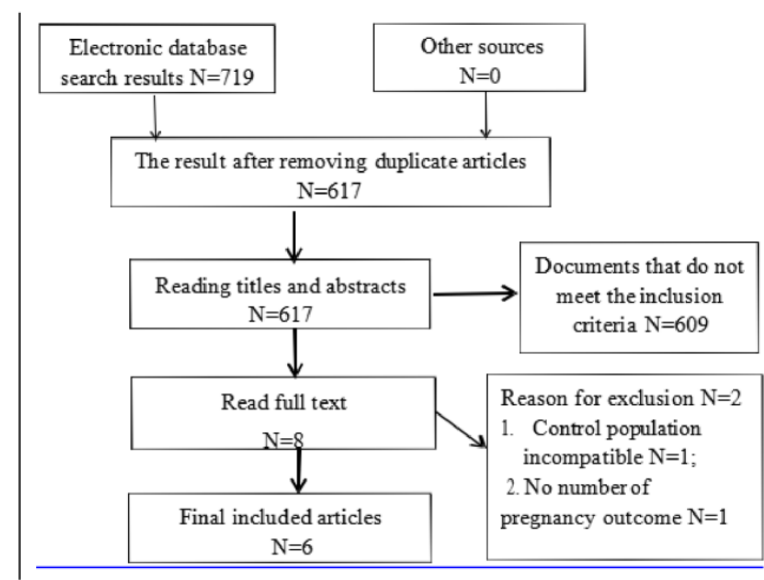




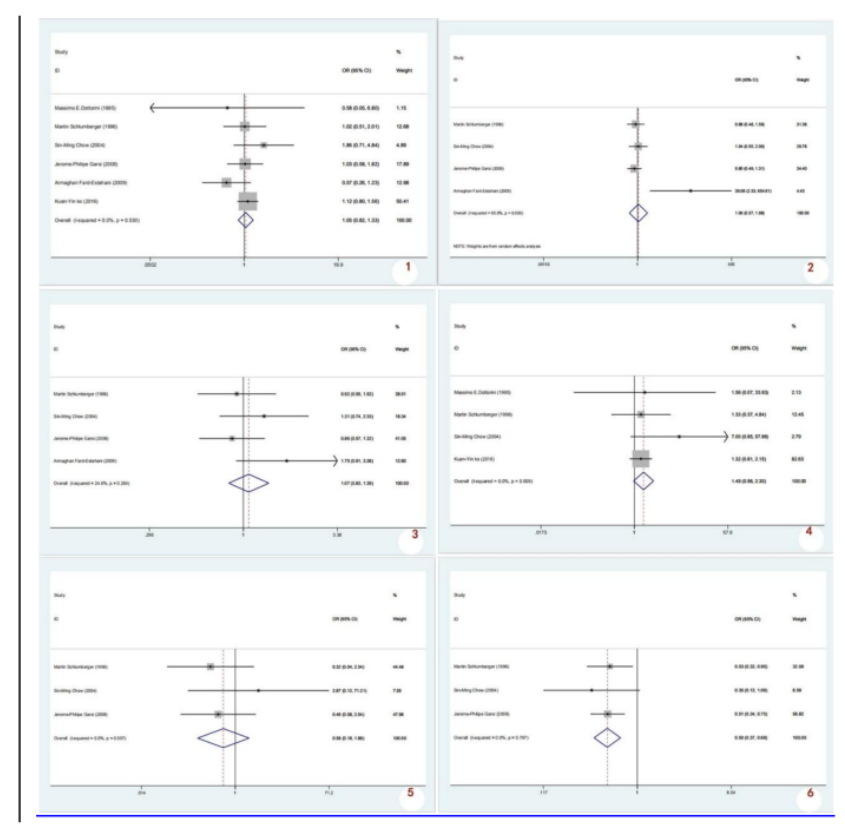




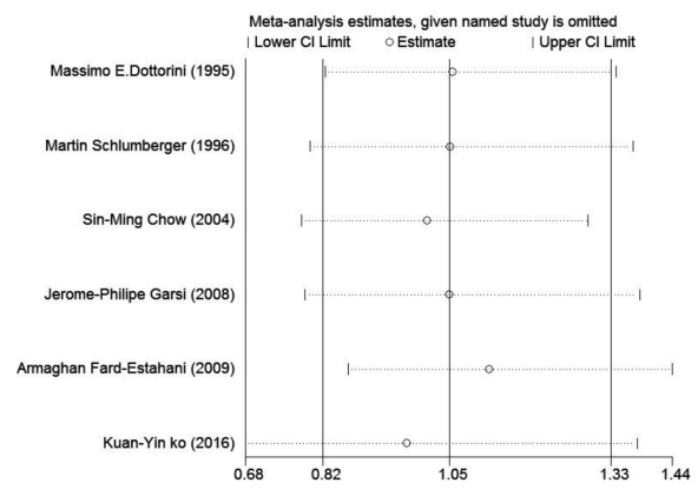

